\title{
The relationship between volatility, volume and open interest: some evidence from the South African futures market
}

\author{
E. vd M. Smit* \& M.W. Louw \\ Graduate School of Business, University of Stellenbosch, P.O. Box 610, Bellville, 7535 Republic of South Africa
}

Received September 1996

\begin{abstract}
Using the methodology devised by Bessembinder \& Seguin, the relationships between volatility on the one hand and volume and market depth in the South African futures market are examined. Daily mark-to-market prices, trading volumes and open interest on six futures contracts traded on SAFEX over the period 1990 to 1994 are utilized. The evidence suggests that linking price volatility to total volume does not capture all information. When total volume is divided into expected and unexpected components, the latter is shown to have a more substantial effect on volatility. Furthermore, coefficients pertaining to open as well as unexpected open interest tend to be negative, implying that lower volatility shocks are associated with a given volume in deeper markets. It is further shown that positive unexpected volume shocks are associated with higher levels of volatility and that asymmetry exists, insofar as positive shocks have larger effects on volatility than negative shocks.
\end{abstract}

*Author to whom correspondence should be addressed.

\section{Introduction}

It has become conventional wisdom to state that a positive contemporaneous correlation exists between volume traded and price volatility in financial markets. Karpoff (1987) referenced 18 separate studies which had documented this relationship in a variety of financial markets. Some of these studies had also documented asymmetry in the relation, in the sense that positive price shocks are associated with larger volumes than negative price shocks.

Karpoff (1987) argues that there are at least four reasons why the price-volume relationship requires better understanding. First, observed relationships between prices and volume can help discriminate between different hypotheses related to market structure. Second, in event studies the validity of tests can depend on the joint distribution of price changes and volume and third, the price-volume relation is critical in the debate about the distributions of speculative prices. In the fourth place, the nature of the price-volume relationship has significant implications for research into futures markets and the understanding of pricing behaviour in these markets.

This research, using the methodology of Bessembinder \& Seguin (1993), investigates two dimensions of the relationship between volatility and volume in the South African futures market. First, this article investigates whether the effect of volume on volatility is consistent by separating volume into an expected and unexpected element. Each element is allowed to have a separable effect on the observed price volatility. The effects of volume shocks on the volatility of prices are also examined to ascertain whether volatility responds asymmetrically to volume shocks depending on whether volume is above or below its expected value.

Second, the contribution of market depth is examined. According to Kyle (1985) market depth can be defined as the order flow innovation required to move prices by one unit. Market depth is proportional to the amount of noise trading and inversely proportional to the amount of private information not yet impounded into prices. It is hypothesized that depth varies with recent trading activity which is proxied by endogenously determined open interest. With large open interest, it is expected that volatility, conditional on contemporaneous volume, will be lower.

In the analysis empirical methods are employed that explicitly accommodate persistence in the volume-volatility relationship.

The research follows on the work of Smit \& Nienaber (1996) who have demonstrated a positive relationship between equity volatility and expected and unexpected trading volumes in both the spot and futures markets. For the Gold and Industrial Indices it has been shown that the unexpected spot and futures-trading volumes have larger effects on volatility than does the corresponding expected trading volume.

Underlying the current research are theories that predict a positive contemporaneous relationship between price volatility and trading volume. The mixture of distributions hypothesis assumes that price variability is monotonically related to volume of the transaction. Price changes are sampled from a mixture of normal distributions with either the volume per transaction, number of transactions, or number of information arrivals per observation unit acting as the mixing variable (Clark, 1973; Epps \& Epps, 1976; Tauchen \& Pitts, 1983; Harris, 1986; and Lamoureax \& Lastrapes, 1994).

With the sequential arrival of information models new information is distributed sequentially in time. This sequential arrival of new information generates both trading and volume price movements, which increase during periods characterized by frequent information shocks (Copeland, 1976, 1977: Morse, 1981; Jennings, Starks \& Fellingham, 1981; and Jennings \& Barry, 1983).

Admati \& Pfleiderer (1988) show that traders with trade timing discretion choose to trade when recent volume is large. This has the effect that transactions and price movements are bunched in time, and the effect of volume on price movements depends on recent volume levels. Kyle (1985), defining depth as the volume of unanticipated order flows required to move prices by one unit, has developed a model which implies that larger volumes support more informed traders. According to this model depth varies with the level of noninformational trading activity. 
It is neither the object of this article to choose between the alternative hypotheses, nor to expose the causal structure between volume shocks and price changes. The primary econometric objective, following Bessembinder \& Seguin (1992), is to document partial relationships between price changes and shocks to volume and open interest while conditioning on the levels of recent activity.

\section{Data and method}

Daily mark-to-market prices, trading volumes, and open interest of six South African futures contracts are analysed over the period 2 May 1990 to 31 January 1994. The contracts investigated are those on the 3-month Bankers' Acceptance (LBA3); the Eskom 168 bond (E168); the Dollar Gold Index (DGLD); the All Share Index (ALSI); the Industrial Share Index (INDI) and the All Gold Index (GLDI). Data were obtained from the South African Futures Exchange (SAFEX).

The percentage change on the daily mark-to-market price is calculated to obtain the daily return. Contracts closest to expiration are used, except within the delivery month in which the contract next closest to expiration is used.

Table 1 provides details of the contracts studied. Mean contract size and mean daily Rand volume are shown. The mean contract size is calculated by taking the total value of the contracts divided by the number of contracts. The All Gold Index contract (GLDI) has the smallest mean (R16 063) as against the 3-Month Bankers' Acceptance contract (LBA3) which has the largest mean contract size of R961 462.

In calculating the mean daily Rand volume, the total Rand value of the contract for the period is used and divided by the number of days when trading actually took place. Here the All Share Index Contract has the largest mean daily volume (R54.7 million), against the Eskom E168 contract which has a mean daily volume of R4.2 million and the Dollar Gold Index with a mean value of $\mathrm{R} 2.3$ million.

Table 2 provides a summary of the means, standard deviations and partial autocorrelations for returns, absolute returns, volume and open interest for each of the six contracts. The most volatile contract is that on the All Gold Index (GLDI) with a standard deviation of return equal to just more than $2.5 \%$ per day. In contrast, the daily standard deviation of the Eskom E168 future is $0.5 \%$.

Table 1 Mean contract size and mean daily Rand volumes of the South African futures contracts for the period 2 May 1990-31 January 1994

\begin{tabular}{lcc}
\hline Contract & $\begin{array}{c}\text { Mean contract } \\
\text { size }\end{array}$ & $\begin{array}{c}\text { Mean daily Rand } \\
\text { volume }\end{array}$ \\
\hline 3-Month Bankers' Acceptance (LBA3) & 961462 & 18293800 \\
Eskom bond (E168) & 76637 & 4160136 \\
Industrial Index (INDI) & 44671 & 31878866 \\
All Share Index (ALSI) & 39247 & 54749497 \\
All Gold Index (GLDI) & 16063 & 23258894 \\
Dollar Gold Index (DGLD) & 37409 & 2339270 \\
\hline Mean contract size = total value of contracts/number of contracts \\
Mean daily Rand volume = total Rand value of contracts for the period/ \\
days when trading took place
\end{tabular}

Returns in general are not predictable, except in the case of the LBA3 contract. By analysing the autocorrelations of the absolute value of a time series, the time series properties of the variance of the original time series are determined (Bollerslev, 1988). Except for the GLDI contract all first order partial autocorrelation coefficients of absolute returns are positive and statistically significant, which implies that one day's absolute return is highly correlated with the previous day's absolute return. For higher order lags there is at least one positive and significant partial autocorrelation for each of these five contracts. This finding is similar to that of Bessembinder \& Seguin (1993) in their analysis of the US market. In the case of the Gold Index Contract, there is no indication of autocorrelation in absolute returns, indicating a random walk. The fact that significant partial autocorrelations are present at higher lags in the case of the rest of the contracts implies that there is some persistence in volatility.

The most active contract on the basis of the mean open interest is the All Share contract, while the Dollar Gold futures market (DGLD) is least active. It is further clear from Table 2 that volume and open interest are highly autocorrelated. The first order partial autocorrelation coefficients for the volume series vary between 0.063 (LBA3) and 0.811 (ALSI). In the case of open interest, all the first order autocorrelations exceed 0.95 .

The last column in Table 2 shows modified five-lag Dickey-Fuller test statistics for the presence of unit roots in the volume and open interest series. This unit root serves as an important first step in partitioning the series into its expected and unexpected components, and examines the stationarity of a time series. The existence of a unit root is rejected for all the volume series, but for only two of the open interest series. After taking first differences the existence of a unit root is rejected for all the series.

As can be seen in Table 3, four of the six contracts show statistical significant correlations between returns and absolute returns at the $5 \%$ level. Two of these correlation coefficients are significantly negative pointing towards negative skewness in returns. There are significant correlations between absolute returns and volumes in only two cases, which is in contrast to the US evidence provided by Bessembinder \& Seguin (1993). They found absolute returns to be highly correlated with trading volumes in each of the eight markets analysed.

To establish the expected and unexpected components in volume and open interest, univariate forecasting methods are used. ARIMA models are fitted assuring that the partial autocorrelations and autocorrelations of the residuals are well within the $95 \%$ limits. Seasonal lengths of five days are used in all calculations. The expected volume or open interest is given by the model forecast, and the unexpected value is the difference between the actual and the model values. Therefore the sum of the expected and unexpected values equal the actual (observed) value. The ARIMA models fitted to obtain the expected and unexpected components for volume and open interest are presented in Table 4.

The method used by Bessembinder \& Seguin (1993) is utilized to iterate between a conditional mean and a conditional volatility equation. The conditional mean equation is of the form: 
Table 2 Summary statistics of futures returns, risk and trading volumes (daily observations 2 May 1990-31 January 1994)

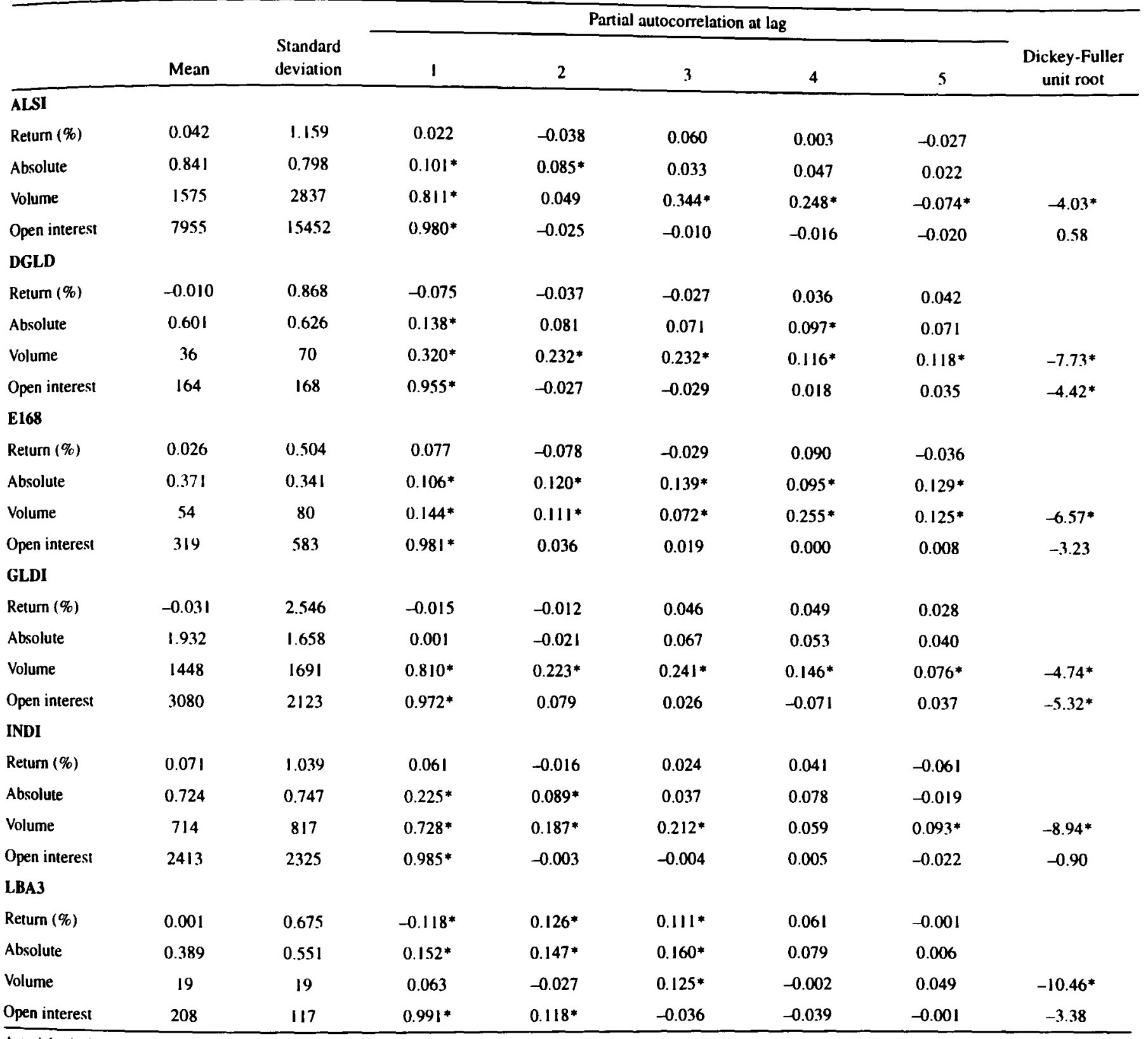

Asterisks indicate partial autocorrelations coefficients which are significantly larger than zero at the $5 \%$ level. Limits are computed in Statgraphics and are equal to $2 / \sqrt{\mathrm{n}}$. In the Dickey-Fuller column * denotes rejection of the null hypothesis of a unit root at the $5 \%$ level.

$$
R_{i}=\alpha+\sum_{i=1}^{n} \gamma_{j} R_{t-j}+\sum_{i=1}^{4} \rho_{i} d_{i}+\sum_{j=1}^{n} \pi_{j} \hat{\sigma}_{t-j}+U_{t}
$$

and the conditional volatility equation

$\hat{\sigma}_{t}=\delta+\sum_{1=1}^{n} \varpi_{j} \hat{U}_{t-j}+\sum_{t=1}^{4} \eta_{i} d_{i}+\sum_{k=1}^{m} \mu_{j} \Lambda_{k}+\sum_{j=1}^{n} \beta_{j} \hat{\sigma}_{t-1}+e_{t}(2)$

where

$R_{1}=$ the return on day $t$

$\mathrm{U}_{1}=$ the residual from Equation 1 representing unex-

$\hat{\sigma}_{\imath}=\left|U_{1}\right| \sqrt{\pi / 2}$ is the estimated conditional return standard deviation on dav $t$ : $d_{i}=a$ dummy variable representing days of the week: and

$\Lambda_{t}=$ an activity variable (volume traded and open interest).

Bessembinder \& Seguin (1993:23) state that if $\mathrm{x} \sim \mathrm{N}\left(0, \sigma^{2}\right)$ then $E(|x|)=\sqrt{2 / \pi) \sigma}$. Since $x$ in this case is a vector of OLS residuals, the assumption that the mean of the distribution is zero is not a problem. However, the distributional assumption of conditional normality must be maintained. The presence of skewness or kurtosis could impart a bias in mean absolute deviation-based estimates of volatility. They further state that the effects of changes in higher moments on inferences made using this class of volatility estimate are negligible for equity returns.

In the conventional regression analysis the following assumptions regarding residuals are usually included: 


\begin{tabular}{|c|c|c|}
\hline & Absolute return & Volume \\
\hline ALSI return & $-0.0715^{*}$ & -0.0092 \\
\hline Absolute return & & 0.0216 \\
\hline DGLD return & $-0.197^{*}$ & -0.037 \\
\hline Absolute return & & $0.209^{*}$ \\
\hline E168 return & 0.034 & 0.043 \\
\hline Absolute retum & & 0.051 \\
\hline GLDl retum & $0.1204^{*}$ & 0.031 \\
\hline Absolute return & & $0.0956^{*}$ \\
\hline INDI return & -0.0303 & -0.0173 \\
\hline Absolute return & & -0.0236 \\
\hline LBA 3 retum & $0.3631 *$ & 0.0343 \\
\hline Absolute retum & & -0.0563 \\
\hline
\end{tabular}

\begin{tabular}{|c|c|c|}
\hline Contract & Volume & Open interest \\
\hline$\overline{E 168}$ & $\operatorname{ARIMA}(2,1,1)(0.0 .1)^{4}$ & $\operatorname{ARIMA}(1,0,0)(0.1,1)^{5}$ \\
\hline LBA3 & $\operatorname{ARIMA}(3,1,0)(0,1,1)^{5}$ & $\operatorname{ARIMA}(1,0,0)(0,1,1)^{5}$ \\
\hline INDI & $\operatorname{ARIMA}(3,0,0)(0,1,3)^{5}$ & $\operatorname{ARIMA}(0,1,0)(0,1,1)^{5}$ \\
\hline ALSI & $\operatorname{ARIMA}(4,1,0)(0,2,3)^{5}$ & $\operatorname{ARIMA}(1,0,0)(0,1,1)^{5}$ \\
\hline DGLD & $\operatorname{ARIMA}(4,0,0)(0,1.2)^{5}$ & $\operatorname{ARIMA}(2,0,0)(0,1,1)^{5}$ \\
\hline GLDI & $\operatorname{ARIMA}(2,0,1)(0,1,1)^{5}$ & $\operatorname{ARIMA}(2,0,0)(0,1.2)^{5}$ \\
\hline
\end{tabular}

- residuals are identically distributed; and

- residuals are independently distributed.

Financial models do not always satisfy these assumptions and information contained in residuals is lost. The model utilizes the information contained in the residuals by following an iterative procedure in which residuals from a first equation are fed into a second equation.

Fitted values from Equation (1) estimate conditional ex-

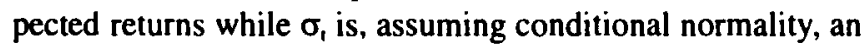
unbiased estimate of the daily return standard deviation. Daily dummies are needed to capture differing mean daily returns, while lagged returns allow for short-term shifts in expected returns. Following Bessembinder \& Seguin (1992), ten lags are used in the analysis. In Equation (2) conditional standard deviations are estimated by regressing those standard deviation estimates on daily dummies, lagged standard deviation estimates and lagged raw residuals obtained from Equation (1). Lagged standard deviation estimates are included to allow for the persistence of volatility shocks. Past unexpected returns are included because past studies indicated that these lags have explanatory power; and including both signed forecast errors and the lagged $\sigma_{1}$, allows for the relation between unexpected return and volatility to vary depending on the sign of the unexpected return. Daily dummies make provision for day-of-the week differences in mean volatilities. All regression analysis is done in TSP using the least squares (LS) method.
In brief, equations (1) and (2) are determined in the following way:

Equation (1) is estimated without lagged volatilities. The transformation

$\hat{\sigma}_{t}=\left|\hat{U}_{t}\right| \sqrt{\pi / 2}$ is then applied to the residuals, and Equation (2) is estimated. Fitted values of Equation (2) are used as regressors in the re-estimation of Equation (1). Lastly Equation (2) is re-estimated by using the residuals from Equation (1).

Share returns are regressed over ten lagged returns to estimate the short-term movements in conditional returns. Dummy variables $d_{i}$ representing the day of the week are included to capture differences in mean returns. The residuals from this regression,

$$
=\hat{\alpha}+\sum_{j=1}^{10} \hat{\gamma}_{j} R_{t-j}+\sum_{i=1}^{4} \rho_{i} d_{i}+\hat{U}_{t}
$$

estimate the unexpected return on day $t$, where the hat ' $\wedge$ ' denotes an estimate. The absolute residual $\left|\hat{U}_{1}\right|$ obtained is then multiplied by the factor $(\pi / 2)^{1 / 2}$ to estimate the standard deviation of the futures return in period $t$. According to Schwert (1990) this estimator is unbiased if the conditional distribution of returns is normal. Next, the conditional volatility equation is estimated by Equation (2).

The trading activity variables, $\Lambda_{k}$, are the expected and unexpected volume and open interest which have been derived by means of the Box-Jenkins technique as described earlier. Fitted values from Equation (2) are then used for the final reestimation of Equation (1). These fitted values are represented by $\hat{\sigma}$ in Equation (1). From this estimation process the coefficients in Table 5 are obtained.

Lastly the residuals from the final Equation (1), (U. $\left.\hat{U}_{1}\right)$, are used to obtain the final conditional volatility Equation (2), of which the coefficients are presented in Table 6.

The effects of trading activity on conditional volatilities are captured by the activity variables, $\Lambda_{k}$, representing volume traded (expected and unexpected) and open interest (expected and unexpected). The expected portion of open interest variable reflects open interest at the start of a trading day, while the unexpected component captures unanticipated changes in net contract formation. As a result, expected open interest is approximately equal to yesterday's level, while the unexpected component approximately equals the change in open interest during the day.

Bessembinder \& Seguin (1993) argue that open interest measures are relevant for two reasons. First, in using open interest together with volume, insights may be gained into the effects of market activity which is generated by informed versus uninformed traders. They argue that many speculators are day traders who dot not hold open positions overnight and that the open interest at close of trading primarily reflects hedging activity which they associate with uninformed trading.

Second, market depth depends on the willingness and abiity of traders to risk capital and position themselves in response to deviations between spot price and perceived fair value. Willingness is dependent on the trader's risk aversion and the ability to trade is a function of wealth. If these 


\begin{tabular}{|c|c|c|c|c|c|c|c|c|c|c|c|c|}
\hline & E $\overline{68}$ & & LBA 3 & & INDI & & ALSI & & DGLD & & GLDI & \\
\hline & Coeff & Prob & Coeff & Prob & Coeff & Prob & Coeff & Prob & Coeff & Prob & Coeff & Prob \\
\hline Intercept & 0.0001 & 0.9303 & -0.0001 & 0.8842 & -0.0002 & 0.9267 & -0.0006 & 0.8485 & 0.0016 & 0.2085 & -0.0031 & 0.5605 \\
\hline \multicolumn{13}{|c|}{ Daily dummies } \\
\hline Monday & -0.0016 & $0.0036^{*}$ & -0.0001 & 0.8882 & -0.0017 & 0.1527 & 0.0001 & 0.9578 & 0.0001 & 0.8869 & 0.0024 & 0.4164 \\
\hline Tuesday & -0.0004 & 0.5000 & 0.0001 & 0.8343 & 0.0006 & 0.5842 & 0.0006 & 0.6524 & -0.0003 & 0.7456 & -0.0036 & 0.1968 \\
\hline Wednesday & -0.0005 & 0.3433 & -0.0002 & 0.7060 & 0.0005 & 0.6479 & 0.0014 & 0.2973 & -0.0002 & 0.8560 & 0.0026 & 0.3568 \\
\hline Thursday & -0.0000 & 0.9567 & 0.0006 & 0.3143 & 0.0001 & 0.937 I & 0.0020 & 0.1428 & 0.0002 & 0.8298 & -0.0020 & 0.4795 \\
\hline \multicolumn{13}{|l|}{ Lagged returns } \\
\hline Lag I & -0.0950 & $0.0069^{*}$ & 0.1236 & $0.0003^{*}$ & 0.0517 & 0.1294 & 0.0088 & 0.7958 & 0.0631 & 0.0722 & -0.0274 & 0.4272 \\
\hline Lag 2 & 0.0702 & $0.0470^{*}$ & -0.1273 & $0.0003^{*}$ & 0.0046 & 0.8946 & -0.0305 & 0.3850 & -0.0255 & 0.4686 & 0.0019 & 0.9554 \\
\hline Lag 3 & 0.0380 & 0.2824 & -0.0723 & 0.0646 & 0.0250 & 0.4814 & 0.0630 & 0.0757 & -0.0273 & 0.4339 & 0.0343 & 0.3218 \\
\hline Lag 4 & -0.0799 & $0.0232^{*}$ & -0.0333 & 0.3948 & 0.0389 & 0.2793 & 0.0078 & 0.8359 & 0.0223 & 0.5205 & 0.0515 & 0.1386 \\
\hline Lag 5 & 0.0587 & 0.0972 & -0.0341 & 0.3821 & -0.0687 & 0.0541 & -0.0178 & 0.6381 & 0.0730 & $0.0499^{*}$ & 0.0185 & 0.5948 \\
\hline $\operatorname{Lag} 6$ & -0.0272 & 0.4433 & -0.1094 & $0.0089^{*}$ & -0.0626 & 0.0820 & 0.0146 & 0.7051 & 0.0433 & 0.2430 & 0.0049 & 0.8882 \\
\hline $\operatorname{Lag} 7$ & -0.0114 & 0.7472 & 0.0051 & 0.9058 & 0.0594 & 0.1108 & 0.0120 & 0.7553 & -0.0988 & $0.0080^{*}$ & -0.0821 & $0.0183^{*}$ \\
\hline Lag 8 & -0.0143 & 0.6997 & 0.0994 & $0.0186^{*}$ & 0.0936 & $0.0127^{*}$ & 0.0783 & $0.0416^{*}$ & 0.0818 & $0.0295^{*}$ & 0.0105 & 0.7617 \\
\hline Lag 9 & -0.0400 & 0.2816 & -0.0755 & 0.0710 & 0.0245 & 0.5143 & 0.0397 & 0.2945 & 0.0950 & $0.0115^{*}$ & 0.0591 & 0.0888 \\
\hline Lag 10 & 0.0189 & 0.6103 & -0.0151 & 0.7176 & -0.0641 & 0.0865 & -0.0078 & 0.8362 & -0.0511 & 0.1798 & -0.0339 & 0.3296 \\
\hline \multicolumn{13}{|c|}{ Standard deviations } \\
\hline Lag I & 0.2169 & 0.1866 & 0.2268 & 0.0758 & 0.0004 & 0.9976 & 0.0444 & 0.8008 & -0.4429 & $0.0100 *$ & 0.1515 & 0.1262 \\
\hline Lag 2 & -0.1805 & 0.2930 & 0.0966 & 0.4843 & -0.0966 & 0.4573 & 0.0083 & 0.9617 & 0.2165 & 0.2125 & 0.0430 & 0.6634 \\
\hline Lag 3 & 0.0372 & 0.8243 & -0.2133 & 0.1234 & 0.1330 & 0.3009 & 0.2102 & 0.2159 & -0.1204 & 0.4811 & 0.1376 & 0.1651 \\
\hline Lag 4 & 0.0607 & 0.7059 & -0.1121 & 0.4238 & 0.0163 & 0.8991 & 0.1927 & 0.2528 & 0.1494 & 0.3772 & -0.0555 & 0.5845 \\
\hline Lag 5 & -0.2451 & 0.1243 & -0.0745 & 0.5873 & 0.1643 & 0.1710 & 0.0575 & 0.7311 & -0.0798 & 0.6345 & -0.0671 & 0.5105 \\
\hline $\operatorname{Lag} 6$ & -0.1569 & 0.3260 & 0.0405 & 0.7443 & 0.2576 & $0.0279^{*}$ & 0.0663 & 0.6857 & 0.4301 & $0.0097^{*}$ & 0.1397 & 0.1727 \\
\hline $\operatorname{Lag} 7$ & 0.4974 & $0.0019^{*}$ & 0.0367 & 0.7660 & -0.1545 & 0.1857 & -0.1953 & 0.2215 & -0.1110 & 0.4911 & -0.0169 & 0.8690 \\
\hline $\operatorname{Lag} 8$ & -0.145 .5 & 0.3643 & 0.0481 & 0.6913 & -0.1680 & 0.1450 & -0.0580 & 0.7018 & -0.0859 & 0.5816 & 0.0120 & 0.9050 \\
\hline $\operatorname{Lag} 9$ & 0.0605 & 0.7008 & -0.0360 & 0.7456 & -0.0735 & 0.5215 & -0.2298 & 0.1256 & 0.0602 & 0.6982 & -0.1405 & 0.1614 \\
\hline Lag 10 & 0.0199 & 0.8958 & -0.0099 & 0.9241 & 0.0191 & 0.8650 & -0.0790 & 0.5973 & -0.2357 & 0.1151 & -0.0687 & 0.4963 \\
\hline Durbin-Watson & 1.9962 & & 1.9958 & & 1.9916 & & 1.9930 & & 2.0104 & & 2.0052 & \\
\hline $\begin{array}{l}\text { Adjusted R- } \\
\text { squared }\end{array}$ & 0.0283 & & 0.0468 & & 0.0210 & & 0.0022 & & 0.0285 & & 0.0056 & \\
\hline F-statistic & 2.0191 & & 2.8121 & & 1.7916 & & 0.9179 & & 2.0221 & & 1.2073 & \\
\hline
\end{tabular}

determinants are fairly stable over time, a variable constructed from lagged open interest should carry information on market depth. Furthermore, the unanticipated daily change in open interest should be a proxy for the willingness of traders to put capital at risk.

\section{Results}

Estimates of Equations (1) and (2) are prepared for each of the six contracts. The results of the estimation of the conditional mean equations are shown in Table 5.

The highest $\mathrm{R}^{2}$-value is equal to $4.7 \%$ in the case of the LBA3 contract. It is therefore clear that there is very little predictive power in the model. Day-of-the-week dummies are not significant except in the case of the Eskom E168 contract, where the Monday dummy is significant at the $5 \%$ level. Lagged returns for Eskom E168 and the LBA3 contract are sig- nificant for lags 1 and 2. All the contracts, except the Eskom E168, show significant coefficients at lags 8 or 7 , or both. For the lagged volatilities no clear pattern is visible; two of the contracts show significance at only one lag, and one at two lags. This provides mixed evidence on the existence of a positive relationship between rates of return and expected volatility.

Table 6 documents the regression results of the conditional volatility equation. Significant lagged volatilities are found in the following cases: ALSI at lag 1; DGLD at lags 4 and 9; LBA3 at lags 1, 2, 3 and 4; E168 at lags 2, 3, 9 and 10; and INDI at lags 1, 4 and 10 .

Generally speaking, the lagged volatilities tend not to be significant seeing that only 14 out of the 60 coefficients are significant. However, persistence is clearly present insofar as 


\begin{tabular}{|c|c|c|c|c|c|c|c|c|c|c|c|c|}
\hline & E168 & & LBA3 & & INDI & & ALSI & & DGLD & & GLDI & \\
\hline & Coeff & Prob & Coeff & Prob & Coeff & Prob & Coeff & Prob & Coeff & Prob & Coeff & rob \\
\hline Intercept & 0.00129600 & $0.0027^{*}$ & 0.00287580 & $0.0000 *$ & 0.00324240 & $0.0008^{*}$ & 0.00604780 & $0.0000^{*}$ & 0.00309590 & $0.0002^{*}$ & 0.01675170 & 0.0000 \\
\hline \multicolumn{13}{|c|}{ Daily dummies } \\
\hline Monday & 0.00044960 & 0.3067 & 0.00029570 & 0.6038 & 0.00362106 & $0.0000 \mathrm{I}^{*}$ & 0.00309710 & $0.0031^{*}$ & 0.00088390 & 0.2867 & 0.00568110 & 0.0051 \\
\hline uesday & 0.00030920 & 0.4761 & 0.00025790 & 0.6467 & 0.00071370 & 0.4344 & 0.00116810 & 0.2537 & -0.00074700 & 0.3555 & 0.00256140 & 0.1950 \\
\hline Wednesday & 0.00002871 & 0.9473 & -0.00000340 & 0.9952 & 0.00039530 & 0.6681 & 0.00133130 & 0.1939 & -0.00074140 & 0.3635 & 0.00273180 & 0.1721 \\
\hline Thursday & 0.00027950 & 0.5258 & 0.00036070 & 0.5256 & 0.00171320 & 0.0620 & 0.00247790 & $0.0164^{*}$ & 0.00061270 & 0.4517 & 0.00485100 & 0.0151 \\
\hline $\begin{array}{l}\text { Jnexpec } \\
\text { olume }\end{array}$ & 0.00000670 & $0.0335^{*}$ & 0.00006359 & 0.000 & 0.00000328 & 0.000 & .00000109 & 0.000 & 0.00002208 & $0.0000^{*}$ & 0.00000926 & 0.0000 \\
\hline olume & 0.00001037 & $0.0003^{*}$ & 0.00008220 & * & 0.00000098 & 0.0886 & 00000039 & 0.0912 & 0.00001692 & $0.0112 *$ & 0.00000269 & 0.0012 \\
\hline open inte & 9 & 0.0 & 1815 & 0.2388 & 0097 & 0.6192 & 0.00000060 & 0.4145 & -0.00001013 & 0.2232 & -0.00000124 & 0.5382 \\
\hline $\begin{array}{l}\text { ected } \\
n \text { intere }\end{array}$ & 8 & 0.3027 & -0.00000889 & $0.0000^{*}$ & 0024 & 0.1868 & -0.00000005 & 0.1677 & 0.00000028 & 8830 & 0115 & 0.0315 \\
\hline \multicolumn{13}{|c|}{ Unexpected returns } \\
\hline ag 1 & -0.01629560 & 0.5769 & -0.00843140 & 0.8093 & -0.03987730 & 0.1703 & 0.09642500 & 0.1313 & -0.01877140 & 0.5480 & -0.00654660 & 0.8005 \\
\hline $\mathrm{ag} 2$ & 0.03230540 & 0.2691 & -0.11520680 & $0.0010^{*}$ & -0.06758410 & $0.0202 *$ & 0.06220780 & 0.0910 & -0.01145130 & 0.7160 & -0.02795920 & 0.2835 \\
\hline ag 3 & 0.01064520 & 0.7160 & -0.02716100 & 0.4403 & -0.05541840 & 0.0574 & 0.02388630 & $0.0402^{*}$ & -0.00464870 & 0.8822 & -0.04585200 & 0.0779 \\
\hline $\operatorname{ag} 4$ & -10.00967800 & 0.7414 & 0.00088170 & 0.9800 & -0.02153230 & 0.4603 & 0.03155030 & 0.3071 & 0.07760060 & $0.0142 *$ & -0.00909750 & 0.7268 \\
\hline Lag 5 & -0.02762750 & 0.3441 & 0.04319630 & 0.2219 & -0.04907280 & 0.0928 & -0.01117560 & 0.1920 & 0.02511100 & 0.4283 & -0.00684170 & 0.7924 \\
\hline Lag 6 & 0.00786940 & 0.7876 & -0.06548180 & 0.0633 & 0.06423370 & $0.0286^{*}$ & 0.00161100 & 0.2406 & -0.00719180 & 0.8205 & -0.00098240 & 0.9697 \\
\hline $\operatorname{Lag} 7$ & -0.07358390 & $0.0116^{*}$ & 0.01020310 & 0.7722 & -0.04600740 & 0.1169 & 0.02916720 & 0.5797 & 0.06188690 & 0.0515 & -0.01229480 & 0.6354 \\
\hline Lag 8 & -0.00752900 & 0.7970 & 0.01848130 & 0.5994 & -0.04662020 & 0.1132 & 0.00454750 & 0.8426 & 0.03113590 & 0.3284 & -0.00586730 & 0.8211 \\
\hline Lag 9 & -0.02436010 & 0.4035 & -0.05778840 & 0.1007 & -0.03107580 & 0.2918 & -0.01706740 & 0 . & 90 & 59 & 2560 & 0.8560 \\
\hline Lag 10 & -0.04678130 & 0.1115 & 0.00755640 & 0.8288 & -0.02187780 & 71 & 336910 & 0.5058 & 0.01918960 & 0.5468 & 0.03860760 & 0.1387 \\
\hline \multicolumn{13}{|c|}{ leviations } \\
\hline Lag 1 & 0.01211700 & 83 & 82440 & $0.0026^{*}$ & 0.19672330 & $0.0000^{*}$ & -0.04419170 & $0.0050^{*}$ & 0.06438920 & 0.0698 & -0.02719360 & 0.4067 \\
\hline 8 & 61970 & $0.0312^{*}$ & 0.08338390 & $0.0194^{*}$ & 0.06558200 & 0.0576 & -0.04956380 & 0.0684 & 0.00466020 & 0.8950 & 0.01362490 & 0.6758 \\
\hline ag 3 & 0.06999100 & $0.443^{*}$ & 0.07227710 & $0.0425^{*}$ & -0.02259850 & 0.5096 & -0.06006190 & 0.4821 & 0.01907520 & 0.5847 & 0.05780760 & 0.0698 \\
\hline $\operatorname{Lag} 4$ & 0.05757920 & 0.0985 & 0.09487860 & $0.0080^{*}$ & 0.08127640 & $0.0173^{*}$ & -0.02991890 & 0.3530 & 0.08161690 & $0.0188^{*}$ & 30270 & 0.1216 \\
\hline Lag 5 & 0.06495300 & 0.0636 & -0.00993660 & 0.7819 & -0.03283970 & 0.3331 & -0.03829090 & 0.7414 & 0.01998090 & 0.5643 & 71430 & 0.7371 \\
\hline Lag 6 & 0.02020580 & 0.5637 & 0.05779650 & 0.1058 & 0.05324260 & 0.1162 & -0.03425040 & 0.9619 & 0.03982870 & 0.2511 & 15290 & 0.7483 \\
\hline Lag 7 & 0.02142060 & 0.5410 & -0.00450550 & 0.8994 & 0.04597150 & 0.1749 & -0.01613360 & 0.3874 & 0.02772000 & 0.4215 & 0.03147850 & 0.3189 \\
\hline Lag 8 & 0.03552170 & 0.3069 & -0.02475 I 90 & 0.4854 & 0.00688020 & 0.8394 & -0.00581030 & 0.8933 & 0.06526200 & 0.0592 & 0.01380780 & 0.6606 \\
\hline $\operatorname{Lag} 9$ & 0.08356330 & $0.0164^{*}$ & 0.01758070 & 0.6155 & 0.00533150 & 0.8748 & -0.04597630 & 0.6133 & 0.12959580 & $0.0002 *$ & 0.021557320 & 0.4177 \\
\hline Lag 10 & 0.17494620 & $0.0000^{*}$ & 0.03633430 & 0.2946 & 0.07360530 & $0.0266^{*}$ & 0.01935710 & 0.9198 & 0.02943270 & 0.3991 & $\$ 0.01563980$ & 0.6206 \\
\hline $\begin{array}{l}\text { Durbin } \\
\text { Watson }\end{array}$ & \multicolumn{2}{|c|}{2.0108} & \multicolumn{2}{|c|}{2.0005} & \multicolumn{2}{|c|}{1.9877} & \multicolumn{2}{|c|}{1.9799} & \multicolumn{2}{|c|}{2.0313} & \multicolumn{2}{|c|}{1.9558} \\
\hline red & \multicolumn{2}{|c|}{0.1222} & \multicolumn{2}{|c|}{0.1669} & \multicolumn{2}{|c|}{0.1336} & \multicolumn{2}{|c|}{0.0563} & \multicolumn{2}{|c|}{0.0977} & \multicolumn{2}{|l|}{0.1746} \\
\hline F-statistics & \multicolumn{2}{|c|}{5.1292} & \multicolumn{2}{|c|}{7.2678} & \multicolumn{2}{|c|}{5.8301} & \multicolumn{2}{|c|}{2.8883} & \multicolumn{2}{|c|}{4.1925} & \multicolumn{2}{|c|}{7.6425} \\
\hline
\end{tabular}

50 out of the 60 estimated coefficients are positive and signifIcant volatilities are present in 5 of the 6 contracts studied.

In analysing the lagged unexpected returns, the Eskom E168 coefficients are negative in seven out of the ten lags, while the Industrial Index and the All Share Index each has nine negative coefficients and the Gold Index has eight. This means that unexpected return shocks tend to be negatively related to conditional volatilities. In the case of the Gold Index, none of the coefficients are significant, while for the Indus- trial Index, two are significant. For the Eskom 168, only one coefficient is significant. In general the lagged unexpected returns are not significant, only six out of 60 coefficients being significant, although 36 are negative, the latter implying that in most cases the unexpected return has a negative impact on volatility. This is in contrast to the findings in the US market (Bessembinder \& Seguin, 1993).

All 12 coefficients for expected and unexpected volumes are positive, while ten are significant at the $5 \%$ level. All the 
coefficients are significant at the $10 \%$ level. The coefficients for unexpected volume are higher than those for expected volume, except for the Eskom E168 and LBA3 contracts, with the highest ratio between unexpected and expected coefficients that of the Gold Index contract at 3.4. A one unit change in unexpected volume has roughly twice the effect on volatility than a unit change in expected volume, which is much less than in the American market where it is approximately seven times, according to Bessembinder \& Seguin (1993).
Except for the Dollar Gold contract all the coefficients for expected open interest are negative. Only two of these are significant, namely for the Gold Index and the LBA3 contracts. This is consistent with the joint hypothesis that: (i) the expected open interest is related to the number of trades or amount of capital affiliated with the market; (ii) that these factors enhance market depth: and (iii) there are lower volatility shocks associated with a given volume in deeper markets and is supportive of the findings in the US market (Bessembinder \& Seguin, 1993).

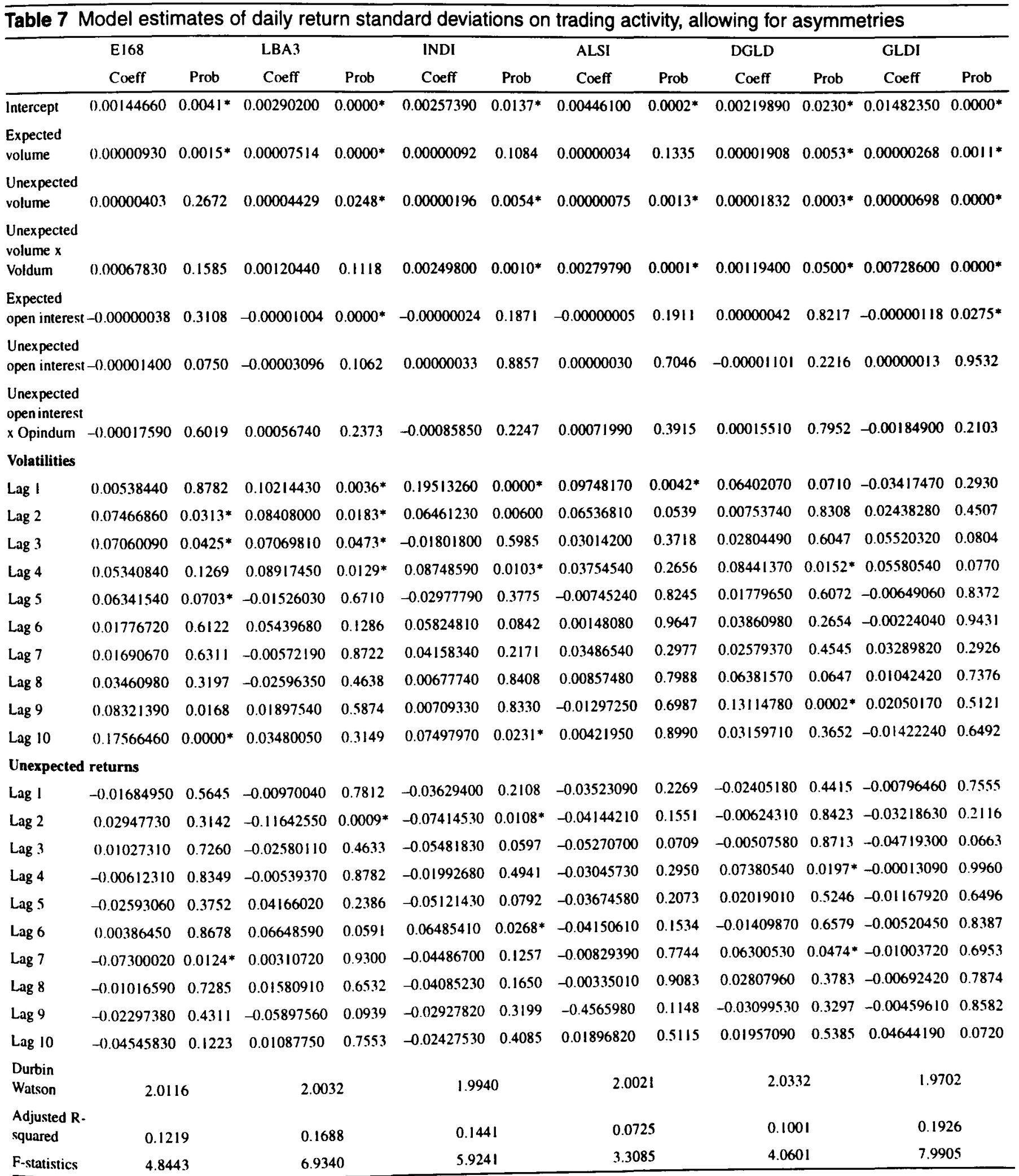


Estimated coefficients relating unexpected open interest to volatility for five of the six contracts are also negative, of which only one, the Eskom 168, is significant at the $5 \%$ level. This means that an increase in open interest during the trading day lessens the impact of a volume shock on volatility. This is also supportive of the findings in the US market (Bessembinder \& Seguin, 1993).

Table 7 shows the results when unexpected changes in volume and open interest on volatility are allowed to vary with the sign of the shock to investigate the existence of asymmetries in volume and open interest shocks. Dummy variables are defined and set equal to 0 for a negative shock (activity below expectation) and 1 for a positive shock (activity above the expected level). Thereafter the product of the indicator variable and unexpected activity series is created. The coefficient associated with the unexpected series represents the marginal impact of a negative volatility shock, while the marginal effect of a positive shock can be determined by adding the coefficients associated with the unexpected series and the cross product. The coefficients for the unexpected volume shocks are all positive. All these coefficients are significant except in the case of the Eskom E168 contract. This means that negative volume shocks are associated with lower levels of volatility. All of the cross-product terms are positive, four of them significantly so. This reinforces the previous finding that positive shocks are associated with higher levels of volatility, and further indicates that positive shocks have a larger effect than negative shocks. Once more these findings support those of Bessembinder \& Seguin (1993).

In the case of open interest, the coefficients associated with unexpected open interest are all positive, although not significantly so. Three of the coefficients associated with the crossproduct term are positive and three are negative, none of them being significant. Here the results are inconclusive and are not supportive of the Bessembinder \& Seguin findings.

According to Kyle (1985), market depth can be defined as the order flow necessary to move prices by one unit. Table 8 shows Rand trading volumes required to move prices by $1 \%$ and the capital required to move prices by the average absolute return. To illustrate, the Rand amount for LBA3 (R769.98 million) when divided by the average value of the contract from Table 1, yields a number of contracts (800), and when multiplied by the estimated coefficient, which links volatility to unexpected positive volume shocks per contract from Table $7,(0.00004+0.0012)$ yields $1 \%$. The probability that the Gold Index will move by $1 \%$ per day is much larger than a similar probability for the LBA3 contract. To accommodate this, the Rand volume needed to move the futures prices by their average absolute return, was calculated. This Rand amount (e.g. for LBA3 = R299.52 million) when divided by the average value of the contract from Table 1 yields a number of contracts (311) and when multiplied by the estimated coefficient linking volatility to unexpected volume shocks from Table $7(0.00004+0.0012)$, yields the mean of the absolute return series for that asset $(0.389$ for LBA3). The rankings do not differ following this approach and it is clear that the depth of the LBA3 contract is the highest while that of the Gold Index is the lowest for unexpected positive volume shocks. The rankings also follow the rankings of comparable contracts in the US market (Bessembinder \& Seguin, 1993).

\section{Conclusions}

It has been shown that the most volatile future contract is that on the All Gold Index (GLDI), while the Eskom 168 (E168) has proved to be the least volatile contract. The All Share (ALSI) contract is most actively traded. as against the Dollar Gold (DGLD) contract, which has been the least active.

Generally speaking, returns in the South African futures market are not predictable from their past histories. Absolute returns, however, show significant autocorrelations which means there is some persistence in volatility. Volume and open interest are highly autocorrelated, while there appears to be no significant correlation between absolute return and volume as in the US market.

Looking at the conditional mean equation, it is clear that there is little predictive power in the models and that day-ofthe-week effects are not significant. Regarding the lagged volatilities, no clear pattern is visible in the data.

In the conditional volatility equation the volatilities show no clear pattern. The lagged unexpected returns are mostly negative, although in general not significantly so. Expected and unexpected volumes both are positively, and in general, significantly related to volatility and a unit change in unexpected volume has roughly twice the effect on volatility as a unit change in expected volume.

The coefficients pertaining to expected open interest as well as unexpected open interest tend to be negative implying that lower volatility shocks are associated with a given volume in deeper markets. When allowing the relationship between unexpected changes in volume and open interest and volatility to vary with the sign of the shock, it is demonstrated that positive shocks are associated with higher levels of volatility and that positive shocks have larger effects than negative shocks. In the case of open interest, this analysis has proved to be inconclusive.

\section{References}

Admati, A.R. \& Pfleiderer, P. 1988. 'A theory of intraday patterns', The Review of Financial Studies, Spring: 1-40.

Bessembinder, H. \& Seguin, P.J. 1993. 'Price volatility, trading volume, and market depth; evidence from futures markets', Journal of Financial and Quantitative Studies, 28: 21-39.

Bollerslev, T. 1988. 'On the correlation structure for the generalized autoregressive, conditional heteroscedasticity process'. Journal of Financial Economics, 9: 121-131.

\begin{tabular}{lcc}
\hline Table 8 & Estimates of market depth \\
\hline & $\begin{array}{c}\text { Capital required to } \\
\text { move futures price } \\
\text { by 1\% } \\
\text { (R million) }\end{array}$ & $\begin{array}{c}\text { Capital required to } \\
\text { move futures price by } \\
\text { average absolute } \\
\text { return (R million) }\end{array}$ \\
\hline Contract & 769.98 & 299.52 \\
LBA3 & 16.18 & 11.71 \\
INDI & 112.93 & 41.90 \\
E168 & 30.34 & 18.24 \\
DGLD & 12.19 & 10.25 \\
ALSI & 1.87 & 3.62 \\
GLDI & &
\end{tabular}


Clark, P.K. 1973. 'A subordinate stochastic process model with finite variances for speculative prices', Econometrica, 41: 135-155. Copeland. T.E. 1976. 'A model of asset trading under the assumption of sequential information arrival', Journal of Finance, 31: 1149-1168.

Copeland. T.E. 1977. 'A probability model of asset trading', Journal of Financial and Quantitative Analysis, 12: 563-578.

Epps. T.W. \& Epps. M.L. 1976. 'The stochastic dependence of security price change and transaction volumes: implications for the Mixture-of-Distributions Hypothesis', Econometrica, 44: 305325.

French, K.R., Schwert, G.W. \& Stambaught, R.F. 1987. 'Expected stock returns and volatility'. Journal of Financial Economics, 19: 3-30.

Gerety, M.S. \& Mulherin, J.H. 1991. 'Patterns in intraday stock market volatility, past and present'. Financial Analysts Journal, September-October: 71-79.

Harris, L. 1986. 'Cross-security tests of the Mixture of Distributions Hypothesis'. Journal of Financial and Quantitative Analysis, 21: $39-46$.

Jennings. R.H., Starks, L.T., \& Fellingham. J.C. 1981. 'An equilibrium model of asset trading with sequential information arrival'. Journal of Finance, 36: 143-161.

Jennings, R.H. \& Barry, C.B. 1983. 'Information dissemination and portfolio choice', Journal of Financial and Quantitative Analysis. 18: $1-19$.
Karpoff, J.M. 1987. 'The relation between price changes and trading volume: a survey', Journal of Financial and Quantitative Analysis, 22: 109-126.

Kyle, A.S. 1985. 'Continuous auctions and insider trading'. Econometrica, 53: 1315-1335.

Lamoureax, C.G. \& Lastrapes. W.D. 1994. 'Endogenous trading volume and momentum in stock-return volatility', Journal of Bustness and Economic Statistics, 12: 253-260.

McGreggor, R. 1989. The mechanics of the Johannesburg Stock Exchange. Second Impression. Cape Town: Juta. 426p.

Morse, D. 1981. 'Price and trading volume reactions surrounding earnings announcements: a closer examination' . Journal of Accounting Research. 19: 374-383.

Schwert, G.W. \& Seguin, P.J. 1989. 'Heteroscedasticity and Stock returns', Journal of Finance, 45: 1129-1156.

Schwert, G.W. 1990. 'Stock volatility and the Crash of 87 ', Review of Financial Studies, 3: 77-102.

Smit, E.v.d.M. \& Nienaber. H. 1996. 'Futures-trading activity and share price volatility in South Africa'. Under review. The Financial Analysts Journal.

Tauchen, G.E. \& Pitts, M. 1983. 'The price variability-volume relationship on speculative markets', Econometrica. 51: 485-505.

Tauchen, G.E. \& Hussey, R. 1991. 'Quadrature-based methods for obtaining approximate solutions to nonlinear asset pricing models', Econometrica, 59: 371-396. 